\title{
Nursing Care in the Functional Disabilities of the Elderly in Primary Health Care: Systematic Review with Meta-Synthesis
}

\author{
Ana Gracinda Ignacio Da Silva1, Maria Bárbara Freire Lameira1, José Eduardo Resende Campos', \\ Luciana Maria Andrade Neri' ${ }^{1}$, Juliana Conceição Dias Garcez ${ }^{1,2}$, Gabriel Fazzi Costa ${ }^{2}$, \\ Maria Rute de Souza Araujo ${ }^{1}$, Milena Farah Damous Castanho Ferreira1, Daniele Melo Sardinha ${ }^{3^{*}}$ \\ ${ }^{1}$ Metropolitan University Center of the Amazon (UNIFAMAZ), Belém, Pará, Brazil \\ ${ }^{2}$ Post-Graduate Program in Parasite Biology in the Amazon, Pará State University, Instituto Evandro Chagas (PPGBPA/UEPA/IEC), \\ Belém, Pará, Brazil \\ ${ }^{3}$ Post-Graduation Program in Epidemiology and Health Surveillance, Instituto Evandro Chagas (PPGEVS/IEC), Ananindeua, \\ Pará, Brazil \\ Email: danielle-vianna20@hotmail.com
}

How to cite this paper: Da Silva, A.G.I., Lameira, M.B.F., Campos, J.E.R., Neri, L.M.A., Garcez, J.C.D., Costa, G.F., de Souza Araujo, M.R., Ferreira, M.F.D.C. and Sardinha, D.M. (2021) Nursing Care in the Functional Disabilities of the Elderly in Primary Health Care: Systematic Review with Meta-Synthesis. Open Access Library Journal, 8: e7431.

https://doi.org/10.4236/oalib.1107431

Received: April 18, 2021

Accepted: May 28, 2021

Published: May 31, 2021

Copyright $\odot 2021$ by author(s) and Open Access Library Inc.

This work is licensed under the Creative Commons Attribution International License (CC BY 4.0).

http://creativecommons.org/licenses/by/4.0/ (c) (i) Open Access

\begin{abstract}
When considering the elderly, we must realize the profound particularities in their daily lives, because the elderly has vulnerabilities that result from the aging process. This study aims to develop a systematic review followed by meta-synthesis based on the findings of qualitative primary scientific research, on nursing care in the face of Functional Incapacity of the Elderly in Primary Health Care starting with the research question: How does the nursing care process for elderly people with functional incapacity occur in primary health care? This is a systematic literature review with the elaboration of meta-synthesis. The search for the articles occurred in the databases of the Regional Portal VHL (Virtual Health Library); Brazilian Digital Library of Theses and Dissertations (BDTD); PubMed, Science Direct, and Google Scholar. The sample consisted of seven original articles of qualitative methodology, one of which was a mixed method. Data analysis followed the guidance of content analysis. The thematic category was identified: The process of nursing care for elderly patients with functional incapacity focuses on primary health care. It was concluded that nurses take care of elderly people with functional incapacity in the basic health unit, at home and in nursing homes, evaluating, planning, and implementing activities that prevent risks, treat complaints and integrate these elderly people into community projects. This care is performed through nursing consultation, integrated into programs, and using tools and protocols.
\end{abstract}




\section{Subject Areas}

Nursing

\section{Keywords}

Nurse, Nursing Care, Old Man, Functional Disability, Primary Health Care

\section{Introduction}

Population aging is a worldwide phenomenon, in 2010 in Brazil the age group of the population aged 60 or over was $11.3 \%$. It is estimated that Brazil will be the sixth country with the largest contingent of elderly people in 2025 [1].

This change in the population demographic profile increases the demand for care for the elderly population and requires a comprehensive, interdisciplinary, multidimensional approach, which considers the interaction between the physical, psychological, environmental, and socio-cultural factors that influence health, including the community, the home and family of the elderly [2].

In this context, the nursing team is indispensable in caring for this population, as it is up to the nurse in addition to administrative, assistance, educational and research functions to develop the process of caring for the elderly. This process must be implemented to enable the organization of care, decreasing the risk of physical dependencies of the elderly person, enabling continuous assessment of functional capacity, and establishing required goals in face of the elderly person's needs, individually, according to their particularities [3].

Functional incapacity of the elderly is a major obstacle faced by nursing professionals, since these functional incapacities are an aggravation of intrinsic and extrinsic factors, generating consequences on natural aging and functional limitations [4].

The intrinsic factors can be determined by the elderly person; such as physical and mental changes related to age, decreased functional capacity, the appearance of chronic diseases, osteoarticular diseases, digestive system, genitourinary system, alteration of vision and hearing, vertigo, loss of muscle strength, sarcopenia and muscle weakness is a universal characteristic of aging; the range of motion, speed of muscle contraction, postural changes influence functional mobility and balance deficit in the elderly, which may be related to skeletal, neuromuscular and sensory muscle systems [5].

It is worth mentioning that, in Brazil, there is a great variation of disability in people over the age of sixty, in men these changes affect about $12.3 \%$ to $94.1 \%$ and in women from $14.9 \%$ to $84.6 \%$, however, according to the author, there are studies that demonstrate that there are no differences in functionality between the sexes, however, elderly people who live in regions with greater income difficulties are more likely to manifest functional impairments [6].

Allied to these aspects, the concern with the problem started from a study car- 
ried out in the 5th period of the bachelor's degree course in nursing, on the Good nursing practices carried out in the Family Health Strategy (ESF) in the Health of the Elderly Program, from of an Integrative Literature Review (RIL), from 2007 to 2017, and problems related to the health of the elderly caused by health conditions or by the physiological aging process itself, as well as the importance of nursing in its process to take care of. Such aspects, motivated the interest to know: How does the nursing care process to the elderly with functional incapacity occur in primary health care?

Therefore, this study is relevant, as it made it possible to systematize evidence from the scientific literature on good practices in the process of caring for elderly people with functional incapacity, contributing to evidence-based practice in this process, benefiting the process of training nurses, their practice professional, enabling safe and effective care in improving the quality of life of the elderly.

The objective of this study was to develop a systematic review followed by meta-synthesis based on the findings of primary qualitative scientific research, on nursing care in the face of Functional Incapacity of the Elderly in Primary Health Care.

\section{Methodology}

It is a systematic review of scientific literature with Meta-synthesis (qualitative), a research modality that performs a systematic review of qualitative investigations through relationships between research, such as comparisons, similarities, and differences, to meta-synthesize the conclusions drawn from the analysis performed. For this, it is necessary that the results found in the analyze be grouped and regrouped by similarities, to answer the guiding question of the research [7].

There are three strategies for the synthesis of results from qualitative studies: The first involves the integration of data from multiple studies developed in a research program by the same researcher. The second consists of the synthesis of the research results of different researchers, who categorize the data information into key variables or use content analysis. The third involves the use of quantitative methods to gather the qualitative results of different studies, and statistical analysis can be carried out, that is, meta-aromatization [8]. In the present study, the second strategy was used, the synthesis of the results from the qualitative categorization of the key variables, identified in the production of the data.

The stages of meta-synthesis consist of seven (7) phases: guiding question, the definition of the data search source, search strategy, inclusion and exclusion criteria, sample selection, evaluation and summary of studies, and, finally, data synthesis [9].

In the first stage of the study, the guiding question of the research was defined: How does the nursing care process for the elderly with functional incapac- 
ity occur in primary health care?

According to Nora [9], this question must be composed of several components related to the anagram PICO: population; intervention (or exposure); Comparation; and outcome (O, outcome, in English). However, when it comes to structuring qualitative studies, the author recommends an adaptation of this anagram, in which the PICO strategy is represented as follows: P corresponds to participants, while I the phenomenon of interest and CO is related to the context of the study.

In this project, the acronym PICOT was used, as defined: the participants (P) the nurse. The phenomenon of interest (I) that will be observed in the research, evidence of the care process applied to the elderly population with functional incapacity. While the context (CO) refers to qualitative primary articles on the process of caring in Primary Health Care for the elderly with functional incapacity. The time ( $\mathrm{T}$ ) was delimited to carry out the scientific search, in qualitative articles in the period from 2013 to 2020 [10].

The second phase defined the data source, which was carried out on national and international electronic databases: Regional Portal VHL (Virtual Health Library); Brazilian Digital Library of Theses and Dissertations (BDTD); PubMed, Science Direct, and Google Scholar.

The third phase corresponded to the search strategy, to achieve the research objectives, searches were carried out through the DeCS (Health Sciences Descriptors) through the VHL-Virtual Health Library. For the search strategy of the articles, the following descriptors will be used, keywords and/or free terms to search for articles: Health of the elderly, frail elderly, and Primary Health Care. DeCS: Nurse, nursing care, elderly, functional disability, Primary Health Care.

The Boolean operator (AND) was used in each database, ensuring safety in the search for studies and a considerable number to develop the research. The study searches were carried out independently by the three researchers on the team. Also used were the descriptors in the terms MeSH (Medical Subject Headings) that are close to the research theme: Nurse, Nursing care, Elder, Functional disability, and Primary Health Care.

The following combination of descriptors and keywords was used to conduct searches in all databases: "Nurse" [descriptor] AND "Nursing care" [descriptor] AND "Elder" [descriptor] AND "Functional disability" [descriptor] AND "Primary Health Care" [keyword].

To meet the fourth phase, inclusion and exclusion criteria were defined. Qualitative primary articles published in journals indexed in national and international scientific bases between the years 2013 and 2020 in the Portuguese language of Brazil and Portugal, in the English and Spanish languages were included. Course Completion Work (TCC), monographs, dissertations, theses written in Portuguese and English, and whose subject was the nurse in primary care for the elderly with functional incapacity.

Studies that did not include the main research object were excluded: studies 
that address the topic in the hospital environment; editorials, journalistic articles, conjunctural analysis, evaluation of protocols, reports of experiences, theoretical discussion of concepts, non-original articles (such as reviews, comments) quantitative and secondary studies, such as bibliographic review, manuals, educational materials, personal information; incomplete version of the manuscript; databases and those published outside the period between 2013 and 2020.

In the fifth phase of sample selection, searches were carried out in August, September, and October 2020 in a database at a time to facilitate the registration of the selected documents. It was carried out independently by the three members of the research team, to determine which articles are relevant to the bibliographic sample. Each researcher used the same strategy to perform the searches, applying time limit filters, and a research article to optimize the results.

The records identified by the reviewers by searching the databases after applying the temporal filter were: at the VHL Regional Portal $(n=1)$ and at the $\operatorname{BDTD}(\mathrm{n}=1)$; in PubMed $(\mathrm{n}=8)$; and Google Scholar $(\mathrm{n}=17,300)$, but due to Google's technical limitations, we only had access to Google Scholar $(\mathrm{n}=1000)$; in Science Direct, a temporal filter and research article were applied, remaining $(\mathrm{n}=118)$, thus totaling 1128 articles in the article identification phase. In additional records identified by other sources $(\mathrm{n}=0)$.

As a result of this process, in the screening, 41 articles were obtained that met the criteria according to the judgment of the reviewers at the first moment, after the removal of nine (9) duplicate articles, 1078 articles were excluded because they did not meet the inclusion criteria, and did not contemplate the main object of the research, studies that addressed the theme in the hospital environment, journalistic articles, protocols, reports of experiences, secondary studies, such as those of bibliographic review, manuals, and educational materials.

The selection of the sample was carried out by reading the title of the research, considering the inclusion criteria, thus studies have already been excluded, whose titles did not correspond to the object of the study. Then, both the abstracts of the studies whose titles were inserted according to the inclusion criteria and the abstracts whose title caused some doubt was read. Abstracts that did not meet the inclusion criteria were discarded.

Then, the three reviewers performed the independent reading of the full texts, of the 41 articles, and, with the help of a fourth reviewer, experienced in the qualitative study and the theme of the study, determined the final eligibility of the articles. After this step, three (3) duplicate articles were removed and 31 articles were excluded due to the quantitative research method, which resulted in a final sample of seven (7) articles, which were included in the qualitative synthesis studies (meta-synthesis). The flowchart-PRISMA (Figure 1) was used to represent this process.

In the sixth phase, to evaluate the abstracts, a script instrument adapted from NORA (2012) and from [11] for data extraction, composed of the following 


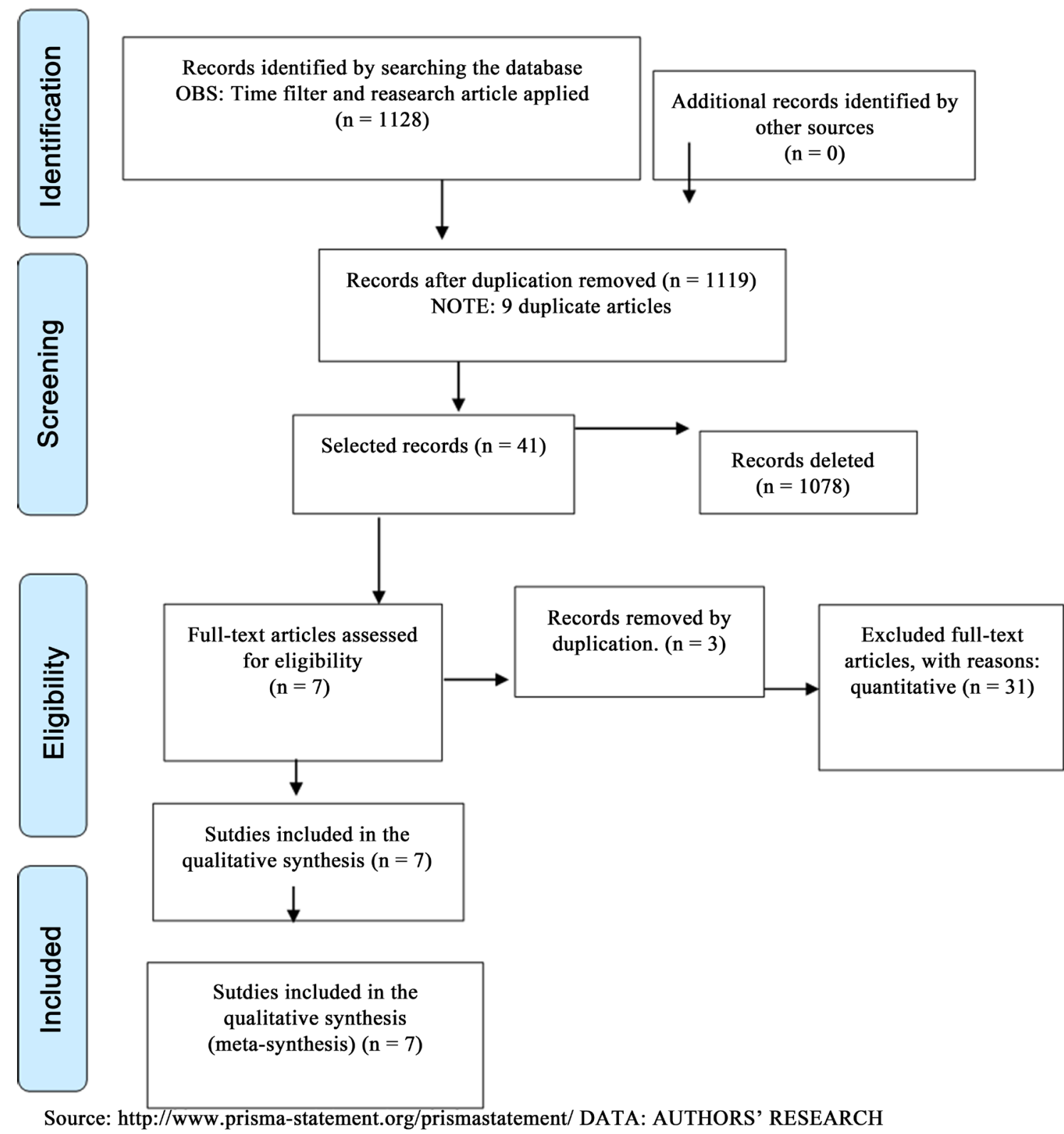

Figure 1. PRISMA flowchart.

fields: Title of the article, authors, year of publication, language, the place where the research was carried out, Qualis of journal, type of study, methodology, number of participants, characteristics of the participants, phenomena of interest, main contributions of nurse care to the elderly with functional incapacity used in national and international EBP, configuration and other information related to the context, conclusion of the author and comments of the reviewer.

Through this instrument, the three reviewers performed successive readings in the seven (7) articles, in full, from which they extracted the data independently. According to the review question, the data were organized in forms adapted by the reviewers, for

Ensure the quality of the process and make the results clear and organized for 
the construction of the synthesis. Then, the reviewers, together, reassessed all the extracted data, reaching a consensus on divergences in the initial assessment.

In the seventh phase, the synthesis of the data was constructed, which was carried out based on the content analysis of the articles selected in three phases: the pre-analysis; exploration of the material, and the data processing, inference, and interpretation Bardin, (2016) [12] I don't have this article). In the pre-analysis stage, the articles were read exhaustively by all researchers independently so that the context and results they brought could be understood, thus appropriating the content of the articles.

In the exploration of material, three summary tables were elaborated for better data organization: Chart 1 was prepared with the characterization of the articles: name of the article, authors, institutions, publication journal, year and place of the research; chart 2, with the name of the article, methodology, objective of the study and chart 3, with the name of the articles and main findings. This organization made it possible to show similar, common, and divergent characteristics between articles, make comparisons about similarities, differences, and complementarities between studies from the significant units of each article. In this way, it was possible to gain mastery over research to develop meta-synthesis.

The phase of data processing, inference, and interpretation, corresponds to the organization of qualitative meta-synthesis that was elaborated from an a priori thematic category, but which was confirmed in the analysis of the articles: The process of nursing care for elderly patients with functional incapacity focus on primary health care. After the elaboration of the qualitative meta-synthesis, the findings were interpreted and discussed with other theoretical references.

\section{Results}

\section{Characterization of articles}

The presentation of the results begins by showing in Table 1 the characterization of the articles used in the elaboration of the meta-synthesis.

Of the articles that were part of this study, two were Brazilian, one Korean, one Canadian, one American, and two Dutch. One article was published in a magazine with A2 quality, two with B1 quality, one with C quality, and three articles it was not possible to identify the quality of the magazines, as shown in the table above.

The articles included 67 nurses who somehow treated elderly people with functional incapacity and focused on care at the primary level of health care, 20 of which were Brazilian; 0 (zero) North Americans; 2 Canadians; 29 Koreans, and 16 Dutch. These nurses were 67 women and 0 (zero) men, aged between 26 and 57 years, with an average of 40.75 years [13] [14] [15] [16] [17].

As for the characteristics of the elderly that these nurses serve, they are elderly aged between 60 and 84 years, in an average of 67.3 years ( $n=50$ Brazil), $(n=28$ Canada), ( $\mathrm{n}=4$ USA), ( $\mathrm{n}=0$ Korea), $(\mathrm{n}=209$ Holland), who have functional 
Table 1. Assets that were part of the study.

\begin{tabular}{|c|c|c|c|c|}
\hline ARTICLES & DATABASE & $\begin{array}{c}\text { YEAR } \\
\text { PUBLICATION }\end{array}$ & $\begin{array}{c}\text { PLACE OF } \\
\text { PERFORMANCE }\end{array}$ & $\begin{array}{l}\text { QUALIS AND } \\
\text { MAGAZINE }\end{array}$ \\
\hline $\begin{array}{l}\text { The praxis of nurses in the family health strategy and } \\
\text { care for the elderly }\end{array}$ & Google Scholar & 2015 & $\begin{array}{l}\text { Florianopolis Santa } \\
\text { Catarina }\end{array}$ & $\begin{array}{l}\text { Text Context Nursing. } \\
\qquad \text { A2 } \\
\text { (ISSN 0104-0707) }\end{array}$ \\
\hline $\begin{array}{l}\text { Community-based primary health care for older adults: } \\
\text { a qualitative study of the perceptions of clients, } \\
\text { caregivers and health care providers }\end{array}$ & Google Scholar & 2015 & Waterloo-Canada & $\begin{array}{l}\text { BMC Geriatrics } \\
\text { B1 } \\
\text { (ISSN: } 1471-2318)\end{array}$ \\
\hline $\begin{array}{c}\text { Process evaluation of a stepped-care program to prevent } \\
\text { depression in primary care: patients 'and practice } \\
\text { nurses' experiences. }\end{array}$ & Google Scholar & 2017 & $\begin{array}{l}\text { De } \\
\text { Boelelaan-Amsterdam- } \\
\text { Netherlands }\end{array}$ & $\begin{array}{l}\text { Bmc Family Practice } \\
\text { B1 } \\
\text { (ISSN: 1471-2296) }\end{array}$ \\
\hline $\begin{array}{l}\text { Nursing Diagnosis of Impaired Physical Mobility in } \\
\text { Elderly People at Primary Health Care. }\end{array}$ & Google Scholar & 2017 & Redenção-Ceará & $\begin{array}{l}\text { International Archives of } \\
\text { Medicine. } \\
\text { Ç } \\
\text { (ISSN: } 1755-7682)\end{array}$ \\
\hline $\begin{array}{l}\text { A nurse-led interdisciplinary primary care approach to } \\
\text { prevent disability among community-dwelling frail } \\
\text { older people: A large-scale process evaluation }\end{array}$ & Google Scholar & 2013 & South Holland & $\begin{array}{l}\text { International Journal of } \\
\text { Nursing Studies } \\
\text { Unidentified (ISSN: } \\
\text { 2320-9186) }\end{array}$ \\
\hline $\begin{array}{l}\text { Examining practical nursing experiences to discover } \\
\text { ways in which to retain and invigorate the remaining } \\
\text { functions of the elderly with a demented and complex } \\
\text { disability in nursing homes }\end{array}$ & Google Scholar & 2018 & Seoul-South Korea. & $\begin{array}{l}\text { Japan Journal of Nursing } \\
\text { Science } \\
\text { Not identified } \\
\text { (ISSN: } 1742-7924 \text { ) }\end{array}$ \\
\hline Approaching Frailty in Primary Care & Science Direct & 2018 & Livonia, MI, USA & $\begin{array}{l}\text { Advances in Family } \\
\text { Practice Nursing } \\
\text { Unidentified } \\
\text { (ISSN: 0037-5675) }\end{array}$ \\
\hline
\end{tabular}

Source: research of authors.

and cognitive degradation, associated with chronic diseases, such as diabetes and high blood pressure, who seek care in health units, or are at home or in nursing homes [15] [16] [17] [18] [19].

The methods used in these surveys are qualitative and included: qualitative and convergent-care description $(\mathrm{n}=1)$, thematic and qualitative analysis $(\mathrm{n}=$ $1)$, mixed-method, however only the qualitative method $(n=1)$ was used, other articles only indicated that it was qualitative $(n=4)$. Among the techniques of data production, it was used: individual consultation; semi-structured individual interviews, and focus group. The sampling was carried out intentionally and one article reported that it was carried out cross-sectionally, as shown in Table 2.

The technique used for data production was the interview in the nurses 'workplace and the patients' homes. Interviewing techniques and questionnaires were applied, such as a structured and thematic workshop, interviews with semi-structured questionnaires $(\mathrm{n}=3)$, focus group and individual interviews, clinical consultation, FRAIL Questionnaire (frailty assessment tool), Patient Health Questionnaire 9 (PHQ-9), and initial quality of life score (EQ5D). Instruments such as MMSE (Mini-Mental State Examination), CHSFSS (Cardiovascular Health Study Frailty Screening Scale), Barthel scale $(\mathrm{n}=2)$, CFS (clinical frailty 
Table 2. Methodological characterization of the studies.

\begin{tabular}{|c|c|c|c|}
\hline $\begin{array}{l}\text { FIRST AUTHOR/ } \\
\text { YEAR }\end{array}$ & PARENTS & METHODOLOGY & CHARACTERISTICS OF PARTICIPANTS \\
\hline Silva, 2015 & Brazil & $\begin{array}{c}\text { Qualitative/ } \\
\text { Convergent-assistance }\end{array}$ & $\begin{array}{l}\mathrm{N}=20 \text {; nurse; age }=26 \text { to } 54 \text { years; Primary Health Care; Continente health } \\
\text { district; public employee, composing ESF team; be developing assistance } \\
\text { activities in the city of Florianópolis-SC for at least six months. }\end{array}$ \\
\hline Park, 2018 & South Korea & $\begin{array}{c}\text { Thematic/ } \\
\text { Qualitative analysis }\end{array}$ & $\begin{array}{l}\mathrm{N}=29 \text {; nurses; age }=26 \text { to } 57 \text { years; hold a bachelor's degree in nursing from } \\
\text { both the university and college; postgraduate studies; doctorate; hospital } \\
\text { experience before going to work in nursing homes. }\end{array}$ \\
\hline Lafortune, 2015 & Canada & $\begin{array}{l}\text { Qualitative } \\
\text { consultation/Focus group } \\
\text { interviews }\end{array}$ & $\begin{array}{l}\text { No. }=28 \text {; informal clients and caregivers; Client: }>65 \text { years; received one or more } \\
\text { forms of CBPHC (community-based primary health care) in the previous month; } \\
\text { they spoke English; they had not been diagnosed with any form of dementia or } \\
\text { cognitive impairment. Formal caregivers: speak English; experience in caring for } \\
\text { family members > } 65 \text { years; received one or more forms of CBPHC in the } \\
\text { previous month. } \\
\text { Health professionals could reflect both their professional roles and their personal } \\
\text { experiences as informal caregivers. } \\
\mathrm{N}=20 \text {; Health professionals; gender (male and female); urban and rural } \\
\text { residents; case managers; occupational therapists; doctors; a nutritionist; a health } \\
\text { promoter; a physical therapist; a social worker; a nurse; a chiropodist; a hospice } \\
\text { coordinator; a registered practical nurse. }\end{array}$ \\
\hline Dunn, 2018 & USA & Case study & $\begin{array}{l}\mathrm{N}=4 ; 2 \text { men and } 2 \text { women; age }>70 \text { years; frail elderly people with a personal } \\
\text { history; a history of orthopedic surgery; cardiological; neurological surgery; } \\
\text { ophthalmic surgery; among other comorbidities. }\end{array}$ \\
\hline Pols, 2017 & Netherlands & $\begin{array}{l}\text { Qualitative/Intentional } \\
\text { sampling strategy. }\end{array}$ & $\begin{array}{l}\mathrm{N}=15 \text { ( } 8 \text { women and } 7 \text { men); seniors; age: } 48 \text { to } 84 \text { years; sex; a history of } \\
\text { depression; current self-depression; type } 2 \text { diabetes mellitus; Coronary disease; } \\
\text { single or multiple chronic physical conditions; Education Level; baseline; severity } \\
\text { of depression (PHQ-9); baseline anxiety severity (HADS); initial quality of life } \\
\text { score (EQ5D). } \\
\mathrm{N}=9 \text {; nurse; experiences; know the Step-Dep program facilitators and barriers; } \\
\text { clinical nurses who were part of primary care with diabetic patients or those with } \\
\text { cardiovascular diseases; mental health nurses. }\end{array}$ \\
\hline Metzelthin, 2013 & Netherlands & $\begin{array}{l}\text { Mixed: Quantitative } \\
\text { (logbooks and evaluation } \\
\text { forms)/Qualitative } \\
\text { (semi-structured and focus } \\
\text { group interviews). }\end{array}$ & $\begin{array}{l}\mathrm{N}=194 \text {; age } \geq 70 \text { years; frail elderly; increased risk of adverse health outcomes } \\
\text { (falls, hospitalization, disability, and death). } \\
\mathrm{N}=45 \text {; health professionals ( } 12 \text { GPs (general practitioner), } 7 \text { practical nurses } \\
\text { implemented the PoC (Pre-care intervention), } 6 \text { occupational therapists, } 20 \\
\text { physical therapists); working in the same region. Clinical nurse (ability to do an } \\
\text { interview (eg, sufficient cognition and hearing), recent contact with the practice } \\
\text { nurse ( }<\text { two months ago), received at least part of the toolbox, seen by at least } \\
\text { one other discipline besides the nurse practice). }\end{array}$ \\
\hline $\begin{array}{l}\text { Araújo Morais, } \\
2017\end{array}$ & Brazil & Cross-sectional/Qualitative. & $\begin{array}{l}\mathrm{N}=50 \text {; seniors; residents in the territory covered by the Basic Health Unit; age } \geq \\
60 \text { years; voluntarily accept to participate in the study; having physical and } \\
\text { mental conditions to answer the questions; sign the Free and Informed Consent } \\
\text { Form; be in a domestic environment at the time established for data collection. }\end{array}$ \\
\hline
\end{tabular}

Source: Data from the authors' research. Adapted from the study of [20].

scale), FACES pain scale, and mobility assessment through physical examination. Employed programs and protocols such as the PACE (All-Inclusive Care Program for the Elderly),

Regarding the analysis of the data in general, they were characterized as a qualitative methodology, but they did not present a theoretical-methodological basis to support the studies, emphasizing the analysis of thematic content. 
Regarding the quality of qualitative studies, it was considered good, as shown in Table 3. For this evaluation, the CASP checklist-Critical Appraisal Skills Program was used [20], and most studies $(n=5)$ [13] [14] [15] [17] [19], were judged to properly report all issues on the CASP checklist. In one of the studies [18] there was no mention of ethical aspects. In other studies [16] the mention of ethical aspects was not adequately reported, other articles were submitted to ethical review [13] [14] [15] [16] [17] [19].

From the results of the studies, the thematic category was verified: Nursing care for elderly patients with functional incapacity focus on primary health care. From which qualitative meta-synthesis is presented.

Theme: nursing care for elderly patients with functional incapacity focus on primary health care

This theme represents the nursing care offered to the elderly with functional incapacity evidenced in the articles that composed this study. It was observed that there is a large contingent of elderly people who have functional and cognitive incapacity needing attention and care from nursing professionals, whether visiting basic health units, whether at home, at home, or in homes that welcome these elderly people.

Nursing professionals care for these elderly people in different ways and at different levels of this process. Based on the demand of these professionals, the health care networks, in this case, guide their care based on the complaints of the elderly, some in a quick reception and nursing consultation focused on their morbid complaints, thus recognizing that they provide guided care in the biomedical model of health care and do not aim at comprehensive care, often driven by the great demand of the elderly and the anxiety to serve everyone. They recognize that despite being aware of the national health policy the elderly person-PNSPI, do not follow its precepts, as they are unaware of them, as well as,

Table 3. Evaluation of the quality of the studies included according to the critical appraisal skills program (CASP).

\begin{tabular}{|c|c|c|c|}
\hline QUESTIONS & YEA & PARTIALLY REPORTED & NOT \\
\hline 1. Were the research objectives reported? & 7 & 0 & 0 \\
\hline 2. Is the qualitative methodology adequate? & 7 & & \\
\hline 3. Was the research design adequate to achieve the proposed objectives? & 7 & 0 & 0 \\
\hline 4. Was the recruitment strategy adequate to the research objectives? & 7 & 0 & 0 \\
\hline 5. Were the data collected in a way that addressed the research question? & 7 & 0 & 0 \\
\hline 6. Has the relationship between the researcher and the participants been properly considered? & 7 & 0 & 0 \\
\hline 7. Have ethical issues been considered? & 5 & $\begin{array}{c}1 \\
{[16]}\end{array}$ & $\begin{array}{c}1 \\
{[18]}\end{array}$ \\
\hline 8. Was the data analysis rigorous enough? & 7 & 0 & 0 \\
\hline 9. Were the results reported clearly? & 7 & 0 & 0 \\
\hline 10. Does the research contribute? & 7 & 0 & 0 \\
\hline
\end{tabular}

Source: Data from the authors' research. Adapted from the study by REIS, et al., 2017. 
they do not use basic tools such as the elderly person's handbook, stressing that they are not even charged about this. Meantime [13] [18].

The clinical consultation in this perspective should use a weakness screening tool, such as the Cardiovascular Health Study Frailty Screening Scale (CHSFSS), which is a validated tool for evaluation, which uses scores ranging from 0 (best) to 5 (worst) with a point marked for each present criterion and classify people as "pre fragile" if they have 1 or 2 criteria present and "fragile" if 3 or more of the criteria are present. The "FRAIL" questionnaire is another quick and easy questionnaire for assessing frailty with five classification criteria: fatigue, resistance, aerobic capacity, disease, diseases, and weight loss. The use of these tools has the advantage of enabling the prevention of weaknesses to maintain or restore physical strength, [18].

One way of caring, too, is to provide educational materials on the prevention and treatment of frailty in the waiting room and in consultations to alert the patient and caregiver about the negative effects of frailty and the health need, screening for frailty, encouraging the involvement of the elderly in community activities that promote their health, such as exercise groups in local recreation or elderly centers, churches and hospitals community outreach programs [18].

In this sense, care for the elderly can also be carried out based on programs and protocols that provide the assessment of the elderly and provide a concrete and safe basis for care planning. One program mentioned is the Integrated Assisted Living Program (IALP) administered by CCAC (Community Care Access Centers), located in the so-called Waterloo jurisdiction area Canada, which serves a high concentration of elderly people with lower economic status and offers services from the needs and expectations of the patients served, encouraging the participation and involvement of family members and caregivers in the process and the discussion about the care that the elderly need. Besides this, the All-Inclusive Care Program for the Elderly (ACPE) located in a community in Livonia, is another care option, which also provides comprehensive coordinated care by an interdisciplinary team designed to support vulnerable older adults in their efforts to remain in their preferred care setting, thereby avoiding placing them in long-term care settings [15] [18].

Besides, clinical nurses who are part of Primary Care with diabetic or cardiovascular disease patients and mental health nurses in Amsterdam-Netherlands, care for their elderly through the Step-Dep program and use a PHQ-9 protocol patient health) which is an appropriate test for tracking depression. This questionnaire is a starting point for the conversation about mental health, serving as an instrument for monitoring and making clinical decisions regarding care for elderly patients, increasing awareness of mental aspects and management of chronic diseases. Besides, self-help courses also improve patient well-being. Due to the preventive approach, patients and nurses experienced better access to mental health care [16] [21].

Interdisciplinary cooperation in this context is evidenced as an important 
factor for the care of elderly patients with functional incapacity, in this case, the nurse acts as a case manager is responsible for the coordination and organization of care. Among the care, actions are: monitoring and accompanying frail elderly people and their caregivers, carried out by the practical nurse, in this case, the evaluation and monitoring must take place through home visits or telephone contacts, discussing with the elderly their preliminary treatment plan, seeking to involve them in decision making so that cooperation and learning occurs. The care plan carried out by nurses must be done in an integrated way to meet the individual needs and preferences of the elderly, thus providing, [17].

The home visit by nurses of the Family Health Strategy program is an opportunity to provide care to the bedridden elderly and with impairment of their functional and cognitive abilities, similarly, this care also happens in nursing homes and is more complex. However, a Brazilian study pointed out that it is not always easy to offer this care, as nurses feel unprepared for this care for the elderly, which indicates a failure in their graduation and continuing education in services for this care. A study conducted in Singapore, in nursing homes, pointed out several nursing cares provided to the elderly with this situation, which starts with the functional assessment of all the elderly who enter the homes and this assessment is repeated daily for the control and prevention of worsening of functional degradation. It is essential to carry out daily observation of the elderly to detect changes in their physical and cognitive functions, monitoring their emotional instability is also important, as it can signal aggravation or appearance of functional and cognitive problems, as well as discomfort, in this context, the communicative function is essential based on verbal and non-verbal responses, senseless reactions and actions of self-recognition of the symptoms themselves. Even when assessing bedridden people without communicative function, nurses can find out if the elderly in this situation have any discomfort [13] [14].

In the case of patients who have some mobility, it is important to assess the motor coordination of the healthy members, the ability of the elderly to climb the bed, the ability to resume walking, and to perform activities of daily living (ADLs). Its goal is to make the elderly as independent as possible and preserve the physical and cognitive functions that are present, stimulating muscles and joints and guiding desirable activities on a repetitive basis so that, with training, they can achieve those essential to life and dignity, such as eliminations, the bath, for example [13] [14].

Another important aspect in this care is the monitoring of emotions in the elderly, as they are indicators of their mental and cognitive condition, for this to maintain eye contact with the elderly considering any form of expression that indicates immediate needs, to offer nursing care that helps the emotional well-being and prevent the degeneration of your remaining functions. It is important to note that nursing in these contexts, when assessing and caring for bedridden elderly people with functional incapacity, must also pay attention to the identification of the presence of physical injuries, the risk of falling, the presence 
of fatigue, pain, and functions of elimination and nutrition. In this sense, communication is an essential basic instrument for nurses in interacting with patients and, the nursing diagnostic classification can contribute to the identification and basis of this care. About this, it is emphasized that research carried out in primary care with the elderly, which pointed out the diagnosis of impaired physical mobility, predominantly present [14] [19].

\section{Discussion}

Nursing care for elderly patients with functional and cognitive incapacity, with a focus on primary health care, takes place in spaces of basic health units, home care, and nursing homes. It is care based on the specific complaints of the elderly and in this perspective, the focus is on the disease in a biomedical model, which does not recognize the national health policy for the elderly (PNSPI).

This aspect was also seen in other studies, where nursing care for elderly patients still has its actions based on the biomedical model, a situation that does not meet the recommendations contained in official documents that regulate the implementation and functioning of the National Health Policy for the Elderly. The difficulty of approaching health promotion practices for the elderly can compromise the stabilization and advancement of nursing care, in addition to contributing to strengthening the culture of stopping promoting health to continue treating only the disease itself. In [22] and [1].

It is worth mentioning that, in the context of primary health care, the emphasis is needed on the effective implementation of public policies through measures that prioritize the promotion of active and healthy aging, the preservation of autonomy and functional capacity, and the enhancement of support networks Social [23]. Thus, when talking about the role of nursing in Primary Health Care in the process of caring for the elderly and their families, it is essential to establish their functional independence, prevent secondary complications, and collaborate to adapt the elderly and family to the new situation [3].

However, this care is also oriented with the use of tools that assess the risk of frailty among the elderly to support preventive and treatment plans for these weaknesses. This is because, the elderly has particularities inherent to the age group that makes them more vulnerable, such as, for example, the decrease in auditory and visual frequency and the impairment of the main functional systems, which can generate intellectual incapacity, functional instability, immobility, incontinence, communicative incapacity, greater risk of developing depression and greater risk of falls [24].

On this, Santos et al. [25] point out that a way to assess the health of the elderly is to use multidimensional assessment, which can be verified through research on their conditions of using functional and cognitive support tools and those related to affectivity.

Still, on these aspects, studies indicate that nursing has several tools that can be used to support its planning and practices aimed at maintaining or restoring 
the functionality of the elderly, such as Mini-Mental State Examination (MMSE), Geriatric Depression Scale (GDS), Clock Design Test (CDT), Verbal Influence Test, Activities of Daily Living (VIT-ADL), Basic Activities of Daily Living (BADL), Instrumental Activities of Daily Living (IADL) and Advanced Activities of Daily Living (AADL) that can offer the elderly a satisfactory quality of life that can meet their special needs during the aging process [25] [26] [27].

The results of this research indicated that, among the practices of caring for the elderly, their participation in community activities such as exercises and extension programs is encouraged. This is important as the study of Maciel [28] since, the practice of physical activities provides benefits in the motor areas, especially concerning reflexes, posture, balance, motor coordination, and the mechanism for executing movements. Preventing arterial hypertension prevents weight gain by decreasing the risk of obesity, helps prevent or reduce osteoporosis, promotes well-being, reduces stress, anxiety, and depression.

Nurses also take care of the elderly, following protocols, and integrate these elderly people into programs with interdisciplinary care, with the nurse as the case manager. It is worth mentioning the care provided by nurses in Primary Care, where clinical nurses also assess the mental health of the elderly under their responsibility. About this, it is emphasized that the nurse has the competence to provide assistance assessing the levels of mental health and planning actions according to the needs of each elderly person. Involve family members to interact in the improvement of the elderly, realizing its importance for psychosocial rehabilitation [29].

Besides, the care and assistance of the nursing team are of paramount importance for the professional to present the proper perception of the determinants of mental health in the elderly, needs to go beyond biomedical knowledge, involves humanized care in biopsychosocial aspects, and when necessary, spiritual of the elderly patient [30].

Among the care actions, we observed: monitoring and accompanying frail elderly people and their caregivers, home visits or telephone contacts, discussing their preliminary treatment plan with the elderly. Care during home visits to the elderly bedridden with these incapacities, and in nursing homes, ranging from functional assessment, control, and prevention of worsening of these incapacities, encourage the maintenance of preserved mobility, make the elderly as independent as possible with repetitive task training basic, prevention of physical injuries, monitoring of emotions and verbal and non-verbal expressions, emphasizing in this context, the value of communication.

These findings are corroborated by studies that point out the effective communications established by nursing professionals with the elderly should be stimulated and interpreted in an articulated way to contemplate the verbal and non-verbal dimensions. Communication is important in the relationship established with the elderly, not only verbal but non-verbal communication, especially body language, as the elderly with their cognitive and sensory limitations are 
sometimes less receptive, but sensitive to the affective climate that can establish [31] [32].

\section{Final Considerations}

In this meta-synthesis it was presented from the perspective of the nurses participating in the researchers analyzed, that nursing care for the elderly with functional incapacity from the perspective of primary health care should be offered according to the individual assessment of each elderly person. This care is offered from different perspectives, such as the biomedical perspective, but also with a focus on health promotion and prevention of worsening of their incapacity. It is care that can be offered in the health unit, but also in-home care, aiming at comprehensive care.

In this sense, it was observed that nursing care for these elderlies, ranges from the assessment of weaknesses, functional capacity, and risks to their physical and emotional integrity, the preservation of integral functions, emotional care, their integration in interdisciplinary programs, community health programs, skills training for daily living activities aiming at their independence in essential activities.

Nursing professionals use several tools that will assist in this care, for this, it is necessary to be prepared to deal with them, knowledge about aging, about policies and protocols that aim to care and care for the elderly.

It is suggested that further studies can be carried out to demonstrate successful experiences in caring for the elderly and in care strategies, mainly in Brazil, including the use of theories, the nursing process, diagnostic classifications, and nursing intervention to support care for this population at a time of fragility and disability.

In this sense, the study contributes to highlighting the care for elderly patients with functional incapacity, both in health units and for those who are bedridden at home or in nursing homes. It also evidenced the need to articulate scientific nursing knowledge to assist these elderlies, individually and supported by scientific knowledge of Nursing science, through their theories and classifications of practices, thus pointing out that the dimensions for this care are complex.

\section{Conflicts of Interest}

The authors declare no conflicts of interest regarding the publication of this paper.

\section{References}

[1] Nakata, P.T., da Costa, F.M. and Bruzamolin, C.D. (2017) Cuidados de enfermagem ao idoso na Estratégia de Saúde da Família: Revisão integrativa. Rev Enferm UFPE Line, 11, 393-402.

[2] Magalhães, K.A., Giacomin, K.C., dos Santos, W.J. and Firmo, J.O.A. (2015) A visita domiciliária do agente comunitário de saúde a famílias com idosos frágeis. Ciência \& Saúde Coletiva, 20, 3787-3796. 
https://doi.org/10.1590/1413-812320152012.07622014

[3] Medeiros, F.A.L., Oliveira, J.M.M., de Lima, R.J. and da Nóbrega, M.M.L. (2015) O cuidar de pessoas idosas institucionalizadas na percepção da equipe de enfermagem. Revista Gaucha de Enfermagem, 36, 56-61.

[4] Nunes, J.D., Saes, M.O., Nunes, B.P., Siqueira, F.C.V., Soares, D.C., Fassa, M.E.G., et al. (2017) Indicadores de incapacidade funcional e fatores associados em idosos: estudo de base populacional em Bagé, Rio Grande do Sul. Epidemiol e Serv Saude Rev Do Sist Unico Saude Do Bras, 26, 295-304. https://doi.org/10.5123/S1679-49742017000200007

[5] de Pinho, T.A.M., Silva, A.O., Tura, L.F.R., Moreira, M.A.S.P., Gurgel, S.N., Smith, A.A.F., et al. (2012) Avaliação do risco de quedas em idosos atendidos em Unidade Básica de Saúde. Revista da Escola de Enfermagem da USP, 46, 320-327. https://doi.org/10.1590/S0080-62342012000200008

[6] Figueirêdo, D.S.T.O. (2019) Fatores individuais e contextuais associados à incapacidade em idosos brasileiros. Universaidade Federal De Minas Gerais, Brazil.

[7] de Alencar, E.S. and Almouloud, S.A. (2017) A metodologia de pesquisa: Metassíntese qualitativa. Reflexão e Ação, 25, 204-220.

https://doi.org/10.17058/rea.v25i3.9731

[8] Fracolli, L.A., Gomes, M.F.P., Nabão, F.R.Z., Santos, M.S., Cappellini, V.K. and de Almeida, A.C.C. (2014) Instrumentos de avaliação da Atenção Primária à saúde: revisão de literatura e metassíntese. Ciência \& Saúde Coletiva, 19, 4851-4860. https://doi.org/10.1590/1413-812320141912.00572014

[9] Nora, C.R.D. (2012) Política de Humanização na Atenção básica uma metassíntese. Universidade do Vale do Rio dos Sinos, Brazil.

[10] Soares, C.B., Formari, L., Pinho, I. and Costa, A.P. (2019) Revisão da Literatura com Apoio de Software: Contribuição da Pesquisa Qualitativa. Ludomedia, São Roque.

[11] Institute, J.B. (2019) Apêndice 8.1 Formulário de Extração de Dados de Métodos Mistos da JBI seguindo uma Abordagem Integrada Convergente. JBI Rev Man, 1, $1-3$.

[12] Bardin, L. (2016) Análise de Contéudo. 70th Edition, Almedina Brasil, São Paulo.

[13] Silva, K.M. and Dos Santos, S.M.A. (2015) A Práxis Do Enfermeiro Da Estratégia De Saúde Da Família E O Cuidado Ao Idoso. Texto e Context Enferm, 24, 105-111.

[14] Park, M.-S., Lim, S.-Y., Kim, E.-Y., Lee, S.-J. and Chang, S.-O. (2018) Examining Practical Nursing Experiences to Discover Ways in Which to Retain and Invigorate the Remaining Functions of the Elderly with a Demented and Complex Disability in Nursing Homes. Japan Journal of Nursing Science, 15, 77-90.

https://doi.org/10.1111/jins.12174

[15] Lafortune, C., Huson, K., Santi, S. and Stolee, P. (2015) Community-Based Primary Health Care for Older Adults: A Qualitative Study of the Perceptions of Clients, Caregivers and Health Care Providers. BMC Geriatrics, 15, Article No. 57. https://doi.org/10.1186/s12877-015-0052-x

[16] Pols, A.D., Schipper, K., Overkamp, D., Van Dijk, S.E., Bosmans, J.E., Van Marwijk, H.W.J., et al. (2017) Process Evaluation of a Stepped-Care Program to Prevent Depression in Primary Care: Patients' and Practice Nurses' Experiences. BMC Family Practice, 18, Article No. 26. https://doi.org/10.1186/s12875-017-0583-7

[17] Metzelthin, S.F., Daniëls, R., van Rossum, E., Cox, K., Habets, H., de Witte, L.P. and Kempen, G.I.J.M. (2013) A Nurse-Led Interdisciplinary Primary Care Approach to Prevent Disability among Community-Dwelling Frail Older People: A Large-Scale 
Process Evaluation. International Journal of Nursing Studies, 50, 1184-1196. https://doi.org/10.1016/j.ijnurstu.2012.12.016

[18] Dunn, D. (2019) Approaching Frailty in Primary Care. Advances in Family Practice Nursing, 1, 87-97. https://doi.org/10.1016/j.yfpn.2018.12.003

[19] Araújo Morais, P.C., Freitas Mauricio, T., Pessoa Moreira, R., Gomes Guedes, N., Soares Chaves Rouberte, E., Freires Ferreira, J.D. and de Lima, P.A. (2017) Nursing Diagnosis of Impaired Physical Mobility in Elderly People at Primary Health Care. International Archives of Medicine, 10, 1-8. https://doi.org/10.3823/2305

[20] dos Reis, S.M.G., Leite, A.C.A.B., Alvarenga, W.A., Araújo, J.S., Zago, M.M.F. and Nascimento, L.C. (2017) Metassíntese sobre o homem como pai e cuidador de um filho hospitalizado. Revista Latino-Americana de Enfermagem, 25, 11. https://doi.org/10.1590/1518-8345.1850.2922

[21] Smeha, L.N. and Oliveira, V.L.P. (2014) Inclusão escolar: A perspectiva das mães de alunos com Síndrome de Down. Revista Educação Especial, 27, 403-415. https://doi.org/10.5902/1984686X5908

[22] Pinheiro, G.M.L., Alvarez, A.M. and de Pires, D.E.P. (2012) A configuração do trabalho da enfermeira na atenção ao idoso na estratégia de saúde da família. Ciência \& Saúde Coletiva, 17, 2105-2115. https://doi.org/10.1590/S1413-81232012000800021

[23] de Araújo, L.U.A., Gama, Z.A.S., do Nascimento, F.L.A., de Oliveira, H.F.V., de Azevedo, W.M. and Almeida Jr., H.J.B. (2014) Avaliação da qualidade da atenção primária à saúde sob a perspectiva do idoso. Ciência \& Saúde Coletiva, 19, 3521 3532. https://doi.org/10.1590/1413-81232014198.21862013

[24] Silva, A. and Dal Prá, K.R. (2014) Envelhecimento populacional no Brasil: Elementos para pensar o lugar das familias na proteção dos idosos. Argumentum, 6, 99-115. https://doi.org/10.18315/argumentum.v6i1.7382

[25] Santos, S.S.C., Carvalheiro, B.C., Silva, B.T., Barlem, E.L.D., Feliciani, A.M. and Valcarenghi, R.V. (2010) Avaliação multidimensional do idoso por enfermeiros brasileiros: uma revisão integrativa. Ciência, Cuidado E Saúde, 9, 129-136. https://doi.org/10.4025/cienccuidsaude.v9i1.5530

[26] Martins, N.I.M., Caldas, P.R., Cabral, E.D., Lins, C.C.S.A. and Coriolano, M.G.W.S. (2019) Instrumentos de avaliação cognitiva utilizados nos últimos cinco anos em idosos brasileiros. Ciência \& Saúde Coletiva, 24, 2513-2530. https://doi.org/10.1590/1413-81232018247.20862017

[27] Magalhães Barbosa, F.B., Biermann, L.S., Peixoto Jr., A.A. and Almeida, G.H. (2013) Transtorno depressivo no idoso: Rastreamento, diagnóstico e aspectos epidemiológicos. Geriatr Gerontol Aging, 7, 228-233.

[28] Maciel, M.G. (2010) Atividade física e funcionalidade do idoso. Motriz Rev Educ Física UNESP, 16, 1024-1032. https://doi.org/10.5016/1980-6574.2010v16n4p1024

[29] Scazufca, M., Menezes, P., Tabb, K., Kester, R., Rössler, W. and Huang, H. (2016) Identification and Treatment of Depression of Older Adults in Primary Care: Findings from the São Paulo Ageing and Health Study. Family Practice, 33, 233-237. https://doi.org/10.1093/fampra/cmv062

[30] Chen, Y.-H., Lin, L.-C., Chuang, L.-L. and Chen, M.-L. (2017) The Relationship of Physiopsychosocial Factors and Spiritual Well-Being in Elderly Residents: Implications for Evidence-Based Practice. Worldviews on Evidence-Based Nursing, 14, 484-491. https://doi.org/10.1111/wvn.12243

[31] Kamińska, M.S., Brodowski, J. and Karakiewicz, B. (2015) Fall Risk Factors in 
Community-Dwelling Elderly Depending on Their Physical Function, Cognitive Status and Symptoms of Depression. International Journal of Environmental Research and Public Health, 12, 3406-3416. https://doi.org/10.3390/ijerph120403406

[32] Clares, J.W.B., Guedes, M.V.C., Silva, L.F., Nóbrega, M.M.L. and Freitas, M.C. (2016) Subconjunto de diagnósticos de enfermagem para idosos na Atenção Primária à Saúde. Revista da Escola de Enfermagem da USP, 50, 272-278.

https://doi.org/10.1590/S0080-623420160000200013 